\title{
Benjamin Crémieux, Inquiétude et reconstruction. Essai sur la littérature d'après-guerre
}

\section{Mireille Brangé}

\section{(2) OpenEdition}

1 Journals

\section{Édition électronique}

URL : http://journals.openedition.org/studifrancesi/3839

DOI : 10.4000/studifrancesi.3839

ISSN : 2421-5856

Éditeur

Rosenberg \& Sellier

\section{Édition imprimée}

Date de publication : 1 décembre 2012

Pagination : 606

ISSN : 0039-2944

\section{Référence électronique}

Mireille Brangé, «Benjamin Crémieux, Inquiétude et reconstruction. Essai sur la littérature d'après-

guerre », Studi Francesi [En ligne], 168 (LVI | III) | 2012, mis en ligne le 30 novembre 2015, consulté le 05 mars 2021. URL : http://journals.openedition.org/studifrancesi/3839; DOI : https://doi.org/10.4000/ studifrancesi.3839

Ce document a été généré automatiquement le 5 mars 2021.

\section{(c)}

Studi Francesi è distribuita con Licenza Creative Commons Attribuzione - Non commerciale - Non opere derivate 4.0 Internazionale. 


\title{
Benjamin Crémieux, Inquiétude et reconstruction. Essai sur la littérature d'après-guerre
}

\author{
Mireille Brangé
}

\section{RÉFÉRENCE}

BENJAMIN CRÉMIEUX, Inquiétude et reconstruction. Essai sur la littérature d'après-guerre, édité par Catherine HELBERT, Paris, Gallimard, 2011 («Les Cahiers de la nrf»), pp. 187.

Après XXe siècle (1924) en 2010 reparaît ce recueil de 1931 où l'A. étudie ensemble «les faits littéraires, les concordances et les divergences qui caractérisent une époque, les formes spécifiques qu'y prennent les œuvres, [...] leurs rapports avec le milieu historique et social, la vision de la vie qui s'y exprime» (p. 8). La même année que les Essais critiques d'Arland et que les articles de Drieu La Rochelle sur «la fin de l'aprèsguerre», il interroge l'inquiétude des années 1920 et envisage la période qui semble commencer. Le lecteur est frappé par la clarté de vision et l'esprit de synthèse de «Une "période": 1918-1930» (pp. 23-25) analysant le sentiment de mobilisme qui assure alors le triomphe de Pirandello dont l'A. fut le traducteur. La période est aussi vue en termes d'inflation littéraire et de dépréciation de valeurs morales parallèlement à celle des cours monétaires. 1930 marque une stabilisation de ces deux mouvements: l'affirmation d'un nouvel humanisme succède à la «tragédie de la connaissance»; la «carence subite de l'originalité» et une «vue moins paroxystique de l'art» au bouleversement du milieu littéraire (p.32). Des «possibilités de rassemblement», des rêves de «croyances communes» sont le nouvel horizon. Les chapitres suivants, reprenant des articles écrits entre 1923 et 1929, déclinent l'inquiétude selon des angles devenus traditionnels dans la critique: la «crise de l'universalisme» (pp.37-44); les «formes dures» de l'esprit d'inquiétude comme le «refus du réel» (pp. 45-56) ou «la faillite du moi» (pp. 57-72), et ses «formes flottantes» («hamlétisme et "valises vides"») (pp. 73-99). 
2 Un esprit de reconstruction travaille aussi l'époque, avec deux renouveaux, catholique et marxiste, vite expédiés, et la recherche d'un esprit européen, auquel l'A. se consacre surtout: après avoir analysé l'inventaire pour lequel Alain et Valéry ont donné à la jeunesse des méthodes de reconstruction du corps et de l'esprit, il s'attache au recul du subjectivisme et de l'introspection et à la tentative de reconstruire un humanisme fondé sur l'action et la permanence des valeurs. Autre facette de cet esprit: la «recherche de l'esprit européen» débouchant sur des voies distinctes: celle de Larbaud ou Giraudoux doit à Stendhal et Gobineau mais ne donne aucun sentiment d'unité européenne; l'«internationale des riches» (pp. 143-144) qu'incarne Morand a surtout une vision, pas proprement européenne, de l'anarchie mondiale; à l'opposé une «internationale des déshérités» (p. 144); enfin un désir de reconstituer une République des Lettres avec des écrivains qui s'attachent à écrire directement pour un public européen. Dénonçant les dangers de dénationalisation esthétique, de politisation ou de «socialisation» de cette littérature, l'A. plaide pour le renouvellement du rôle européen de la France comme carrefour des idées, au premier chef par les traductions. Au-delà des symptômes d'inquiétude, les années 1930 devraient équilibrer une «aspiration vers le totalisme» encore protéiforme (pp. 165-170).

3 En appendice, la Réponse à une enquête sur les maîtres de la jeune littérature parue dans «La Revue hebdomadaire» en 1922 et L'Homme et la bête de 1926. 